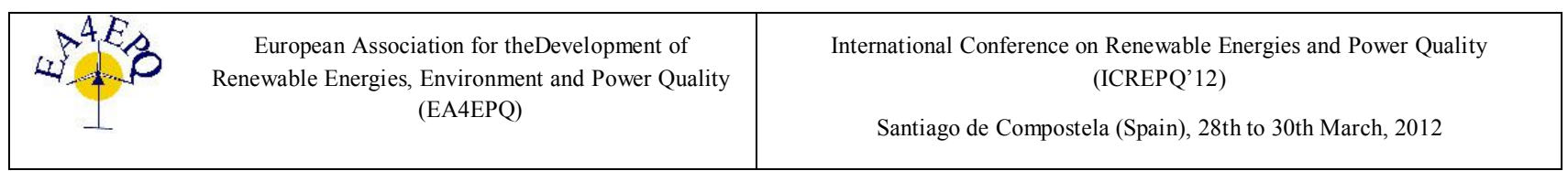

\title{
Strategies to Reduce the Use of Fossil Fuels
}

\author{
Roberto C. Betini ${ }^{1}$ \\ ${ }^{1}$ Departamento Acadêmico de Eletrotécnica - Universidade Tecnológica Federal do Paraná \\ Av. Sete de Setembro, 3165. Phone/Fax number: (+55) 41-3310-4792/(+55)41-3310-4629 \\ CEP.: 80230-901 Curitiba - PR - Brazil \\ e-mail: rcbetini@terra.com.br
}

\begin{abstract}
.
Energy and environmental safety are problems of first greatness faced by our global economy. This article discusses the strategies to reduce the use of fossil fuels.
\end{abstract}

\section{Key words}

Energy and the environment, planning and control of the power system take into account the renewable energy, energy and the greenhouse effect.

\section{Introduction}

Energy and environmental safety are problems of first greatness faced by our global economy. Fossil fuels, particularly the raw oil, can be found for commercial exploration in some areas of the world and the continuity of its supply is governed through dynamic factors such as: political, economical and ecological.

These factors conspire to generate a climate of instability that produces high prices of fuels on one side while, at the same time, an environmental politics is demanding a reduction of emissions of poisonous gases and of greenhouse effect. Still, the increase of the growth and a larger demand for the well-being on the part of the developed and in development countries are factors that are exercising a larger pressure on the use of sources of energy.

In matter, a great fraction of new consumers in developing countries already reached a high purchasing power enough to guarantee them the world access to any article type and market of energy. This high power of purchasing impels the consumption of energy and the competition for all of the types of resources or goods. Such a tendency, although in the beginning it can represent a progress in relation to conquest of the wealth distribution and well to be as well as in such necessary social equality, it is contributing in the moment to these countries to have hurry for the appropriation of available resources that are directly and indirectly connected to the consumption of energy. Consequently, if this fact doesn't go appropriately understood and managed it can be an important factor to generate a planetary instability. Therefore, a strategy for the generation and coherent consumption of energy is requested.

This strategy should focus the supply and the demand of energy, the safety in the access the energy, development problems, social equality, market dynamics, taking into account the whole life cycle of the energy. Important questions as the production of fuels, transmission and distribution, conversion of energy, and the impact on the manufacturers of equipment of energy and over the final users of the systems of energy have also to be considered.

Subjects related to the energy efficiency and the effect of its repercussion should also be taken into account. In the short period, the objective is to reach a larger energy efficiency and increase of the supply of local sources of energy, in matter, renewable sources of energy. In the long term, it would be interesting to change our lifestyles, to increase still more the use of alternative sources of energy and to migrate for dealerships that supply new types of energy just as the hydrogen, what could contribute to solve or to relieve the problems generated by the decrease of the readiness of fossil fuels. 
This whole climate justifies an urgent need to establish strategies for the production and consumption of sustainable energy.

This article suggests research strategies and development for the reduction of the use of fossil fuels tends in view the world economical growth provoked mainly by the countries formed by the BRICs. This economical development that not always takes into account the social aspect, environmental and technological, it is not almost always sustainable and it has been causing the increase of the emission of greenhouse effect gases, the abnormal growth of the temperature and of the level of oceans and provoked irreversible environmental disasters.

\section{The Consumption of Fossil Fuels and the Greenhouse Effect}

With the frequent occurrence of environmental disasters caused mainly due to the increase of the average temperature of the planet because of the human activities, as much the scientific community as the society in general started to use the term global heating to characterize these climatic abnormalities. Climatic abnormalities as hot winters, violent storms, a drastic increase of the temperature in certain periods of the year in that should be smaller has been characterized as a result of the global heating. We can define the global heating as being a significant increase of the average temperature of the Earth in a short period, in reason of the human activity (UNITED, 2010; Weier, 2010).

Thousands of years can pass so that the Earth warms up or just cool a degree Celsius. And that, in fact, happens in a natural way. Besides the cycles of glacial periods, the climate of the Earth can modify because of the volcanic activity, of the differences in the vegetable life that copper most of the planet, of the changes in the amount of radiation that the Sun emits and of the natural changes in the composition of the atmosphere (Purdue, 2008).

An increase of the average temperature of the Earth starting from $1^{\circ}$ Celsius during 100 or 200 years characterizes the global heating. A $0,4^{\circ}$ Celsius elevation in 100 years is already a reasonable value. The Intergovernmental Panel on Climate Change notices that during the passed century the average temperature of the surface of the Earth had an approximate increment of $0,4^{\circ}$ Celsius to $0,8^{\circ}$ Celsius (Metz et all, 2007).

Just in the years of 2008 and 2007, since the temperature measurement began in 1979 , there was less ice in the area of Arctic. The year of 2010 was the hottest year of the whole historical series of measurements. The average of temperatures registered in the first eight months were equaled to the one of 1998, that was the isolated record until then, according to data of the National Center of Climatic Data of the USA ( NATIONAL, 2010(a); NATIONAL, 2010(b)).

The intensification of the greenhouse effect is today one of the main concerns of governments and of international institutions linked to the problem of the global heating. Elaborated estimates have about two decades indicated that the greenhouse effect would cause the global heating, with average temperatures improving from $1^{\circ}$ Celsius to $4^{\circ}$ Celsius during the 21 century. The best knowledge today available about it corrected the estimate down from $1^{\circ}$ to $1.5^{\circ}$ Celsius and it allowed to have a better idea of the possible consequences of that effect.

When the sunbeams arrive to the atmosphere and the surface of the Earth, about $70 \%$ of the energy is absorbed by the soil, oceans and plants, after this the Earth irradiates this heat for the atmosphere. The remaining $30 \%$ are reflected for the space by the clouds and other reflective surfaces (Stories of American Energy Uses, 2010). The layers of the atmosphere that are around of the Earth and that absorb the heat of the Sun also irradiate this heat. A part of this heat goes for the space, and the another part is absorbed by the atmosphere gases like the carbon dioxide and methane gases and steam of water. The heat kept by the terrestrial atmosphere turns the planet hotter than the sidereal space, because the atmosphere is keeping more energy than liberating. This situation of maintaining the Earth hotter due to the retention of energy by certain types of existent gases in the atmosphere is the greenhouse effect.

The greenhouse effect is a meteorological phenomenon very complex of being studied. There is many mechanisms that can increase or to reduce the greenhouse effect. As several authors, some of those mechanisms can retro-feed the effect positively and to result in catastrophes of unexpected results. On the other hand, the greenhouse effect provides the appropriate temperature to the biological processes.

The Earth without the greenhouse effect probably would be like Mars (Freudenrich, 2010) presenting very low temperatures for not having a thick atmosphere enough to keep the heat in the planet. Some scientists suggested the transformation of the Martian surface through the installation of generating factories of carbon dioxide and steam of water in the atmosphere. In case an enormous amount of those gases was generated, the Martian atmosphere could begin to thicken to such a point that would keep more heat and, consequently, it would allows plants to survive and to disperse in its surface causing the production of oxygen. Consequently, with the passing of the centuries, thanks to the greenhouse effect (Bonson, 2010), Mars could have a favorable atmosphere to the survival of the human species in its surface.

The rich countries, especially the USA, resist in following a control program and stabilization of emission of greenhouse effect gases, due to the relationship that the amount of emission of these gases has with the use of fossil fuels to generate energy in their production systems. In agreement with data of the International Agency of Energy (IEA) the fossil fuels were responsible for approximately $77 \%$ of the world energy supply in 1990. Now AIE estimates that this index approaches $87 \%$.

The fossil fuel possesses several uses, however it is extremely pollutant and its disordered use contributes to the global heating, it unchains acid rains, it emits gases that pollute the atmosphere and contaminates the hydro 
resources. The main greenhouse effect gases generated by the consumption of the fuels fossils are $\mathrm{CO}_{2}, \mathrm{CH}_{4}$, $\mathrm{N}_{2} \mathrm{O}$ and the steam of water.

Due to the fact of the $\mathrm{CO}_{2}$ to absorb the infrared radiation, its concentration increase in the terrestrial atmosphere is a preoccupying factor in the global heating. Because most of the energy that it is expelled by the terrestrial atmosphere is through infrared rays and an increase of $\mathrm{CO}_{2}$ in the atmosphere causes a larger retention of the energy than it would be thrown in the space, causing this way, a total increase in the temperature of the planet (NOOA, 2007).

Worldwatch Institute affirms that the emissions of $\mathrm{CO}_{2}$ all over the world are increasing. To have an idea of this growth, from 1900 to 1995 the emissions increased from one billion tons for approximately seven billion tons. Regarding the average temperature of the surface of the Earth, the Institute affirms that it increased from $14,5^{\circ} \mathrm{C}$, in 1860 , to $15,3^{\circ} \mathrm{C}$ in 1980 (WORLDWATCH, 2010).

Great interest exists to know the amount of greenhouse effect gases that are generated by the several sources, as well as about the capacity of absorption of possible drains of these gases to improve the forecasts of variation of the temperature. We presented in the Figure 1 a comparison between the consumption of fossil fuels and the increase of the concentration of carbon in the atmosphere starting from the year of 1800 to the year of 2000 .

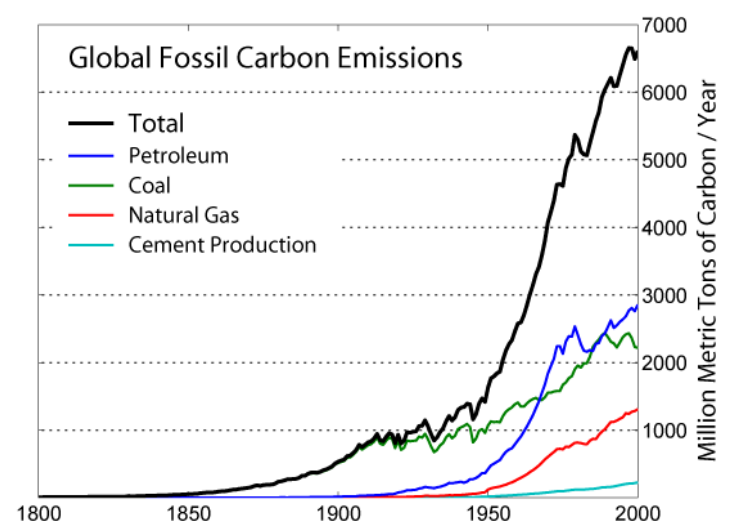

Figure 1: Global emissions of Carbon from the use of fossil fuels. Source: adapted of IPCC, 2007 (Metz et al., 2007).

In the Figure 2 we showed that since the year of 1860 to the year of 2000 there was an increase of the average temperature of 5 years of the surface of the Earth around $0,8^{\circ} \mathrm{C}$.

These results of measurements of concentration of carbon starting from 1800 were obtained from analysis of samples of air contained in layer of polar ice, and information on the forest stock, obtained of the exam of rings of growth of trees. These studies allowed to establish a base of information of the which one can deduce the contribution of the fossil fuels for the increase of concentration of atmospheric carbon (Metz et all, 2007). With the industrialization we had the beginning of the consumption of fossil fuels in great amount. Starting from the century XVII, the mineral coal passed to be used in the production of iron, firstly in England, and in the beginning of the century XIX is widely used at the market of fuels. In the century XX the consumption of petroleum begins to become significant, and later the one of natural gas. Already in the second half of the century $\mathrm{XX}$, the consumption and emissions resulting of the petroleum cross the coal. The pattern of increase of emissions during the period is clear and it might have been one of the responsible for the alteration of the composition of the atmosphere.

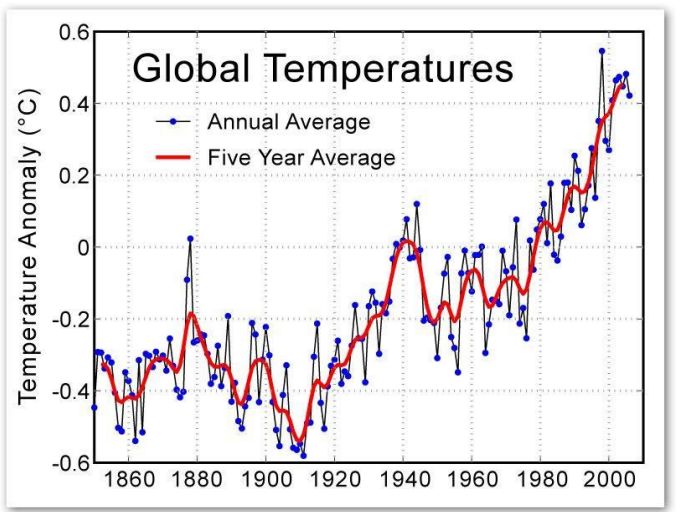

Figure 2: Evolution of the average of maximum global temperature obtained since the year of 1840 to the year of 2004. Source: Adapted from NASA's Goddard Institute for Space Studies (GODDARD, 2010).

The carbon emitted by the biotic sources and by the use of the energy it is absorbed partially by the biomass and the oceans, being the remaining in the atmosphere. This last part is the cause of the concerns in short period. Naturally, it is impossible to discriminate the Carbon in accordance with its origin, so that a confrontation between the emission and the retention in the atmosphere will refer to the existent total carbon. Besides this discrimination difficulty, the carbon is emitted in the form of several composed gaseous, as the carbon dioxide $\left(\mathrm{CO}_{2}\right)$, the carbon monoxide $(\mathrm{CO})$ and hydrocarbons, as the methane $\left(\mathrm{CH}_{4}\right)$. In a medium period, the compositions less stable will decline in $\mathrm{CO}_{2}$ according to varied processes and with different characteristics. Some decline reactions are induced by radiations, creating new mechanisms of retro feeding (Metz et all, 2007).

We concluded this way that the emission of carbon is increasing year to year and this is due mainly for the use of fossil fuels.

Therefore, for the reduction of the greenhouse effect it is necessary to reduce mainly the amount of carbon in the atmosphere and this can be made through the substitution of fossil fuels, mainly, for fuels that don't liberate carbon.

\section{Global heating and their Consequences}

The considerations that will be done in this section don't have the interest of presenting an apocalyptic picture caused by the climatic changes however only to present what has been researched around possible consequences that we should suffer in case we cannot revert the scenery of foreseen global heating. 
Some of the possible effects of the global heating are the flood of low islands due to the increase of the sea level, larger frequency of strong storms and the melting of the glaciers and polar caps (Parry, 2007).

Glaciers and plates of ice around of the world can begin to melt. In fact, this is already happening (NASA, 2010).

The loss of great areas of ice in the surface can accelerate the global heating, because less solar energy will be reflected outside of the Earth. The immediate result of the melting of the glaciers would be the increase of the sea level. Initially, they would only be 2.5 or $5 \mathrm{~cm}$, however, if the plate of ice of the Occidental Antarctic melted and fell on the sea, it would elevate the sea level in more than 10 meters (Metz et all, 2007; Parry et all, 2007), and many coastal areas would disappear completely under the ocean.

The sea level would also rise because the waters of the ocean would be hotter, causing the expansion of the water. Even a modest increase in the sea level would provoke inundations in low coastal areas. IPCC esteems that the sea level has gone up 17 centimeters during the XX century. Projections done by scientists show that up to 2100 year the sea level will arise more 18 to $55 \mathrm{~cm}$ (Metz et all, 2007). Brazil is not among the 50 countries more threatened by the elevation of the sea level.

With the increase of the global temperature of the waters, the storms formed in the ocean would be more numerous and strong, such as tropical storms and hurricanes, that extract their ferocious and destructive energy from the warm waters for the which they pass.

In temperate areas with four very defined stations, the planting station and germination would be longer and with larger incidence of rains. This would be beneficial of many forms for these areas. However, the less temperate parts of the world would probably see a temperature increase and a brutal decrease in the index of rains, causing long drought periods and the appearance of deserts.

The effects on the biodiversity would be the most difficulty to be foreseen and the most devastating. Many ecosystems are delicate, and the subtlest climate change can extinguish several species, as well as any another that depend on them. The ecosystems are, in its great part, interconnected to each other, and the chain reactions of the effects would be immeasurable. The results could be as a forest dying gradually and becoming pasture areas or reefs of corals dying. A lot of species of plants and of animals would adapt or they would change with the alteration of the climate, but many would extinguish.

The Amazonian can lose, for fault of the global heating, from 10 to 25 percent of its forest area, substituted for a type of savanna (Nobre, 2005).

The human cost of the global heating is difficult to be calculated. Thousands of lives would be lost all of the years, since the seniors or patients would suffer with the excess of heat and other traumas related to it. The people of low income and the underdeveloped nations would suffer the worst effects, because they would not have financial resources to work with the problems that would come with the increase of the temperature. An enormous amount of people would die from hunger if the decrease of the rains limited the growth of the crops. They would also die for the increase of diseases caused by present parasites in the water, brought by coastal inundations and for the enlargement of tropical areas, favorable for the development of certain parasites and vectors of diseases that before would be restricted, but that, with the increase of the temperature they would tend dispersing for a larger area (Parry et all, 2007).

\section{How to Avoid or to Delay these Catastrophes}

There are a lot of actions that we can do to try to stop the global heating. Basically, all suggest the reduction in the emission of greenhouse effect gases. To attack these objectives we suggested the implantation of the development and research of the following strategies.

4.1) Improve the Energetic Efficiency. The increase of the energy efficiency will cause the smallest consumption of energy. As the global energy matrix is supplied mainly by fossil fuels, the decrease of the consumption through energy efficiency would cause a decrease in the emission of greenhouse effect gases.

The increase of the Energy Efficiency (in buildings, in systems related with the transport and the infrastructure, and in sections of the production) is a priority that cannot be disrespected. And the society should be educated to reach this objective.

4.2) Decentralization of the energy production improves the performance of the system. We should decentralize the production of energy. Generating heat and electricity locally through generating units of energy of small or average scale, making possible the economy obtained with little investment need in infrastructure of transport of energy. This politics makes use of available resources locally such as the biomass, residues, and small deposits of energy.

A good planning accomplished in generating units of energy of small or average scale can prevent losses of energy efficiency and environmental destruction thanks to an easier administration. The distributed generation avoids also that small generating sources of energy (wind, photovoltaic and hydraulic systems) have its energy potential unexplored or used partially. This initiative also foments the social inclusion, the distribution of incomes and the environmental preservation through the use of residues or garbage, of small generating sources as the case of the small wind, solar, hydraulics and biomass plants.

Decentralized systems of small scale, with the use and production of renewable energy locally seem to be more easily managed and safe with respect to the risk of a natural disaster or even of a terrorist attack or of a discontinuous operation. The small or medium size means that such plants and devices are not an attractive object for terrorism, because they don't wake up the interest of the media and of the general public. Not even the stop possibility or the destruction of those plants can generate great environmental impacts to the adjacent area. Finally, nor the total stop of these plants for an eventual accident could affect the local economy 
significantly, due to possible substitution of the supply of local energy through supply of energy through other neighboring system or national grid. Small generation plants are also less sensitive to the international market of energy due to the cost fluctuation and supply availability. Finally we can still point out that small generation plants could contribute in the distribution and generation of local income. I could be also used as instrument for social inclusion.

4.3) There is the need of the prediction of consumption of energy, both in amount terms and quality. This can be easily obtained when we have an environment composed by the domestic section and, agricultural and industrial enterprises of small size. This way it is motivated the implantation, administration and control of small grids instead of large grids.

4.4) It is important to motivate the use of systems and technologies of zero emission through public politics and education programs addressed to the population. These technologies should be used in chains of local production systems seeking the easiness in the changes of energies and the use of resources no used, preventing these resources of to be transformed in garbage or be discarded. This attitude of doing more with minus, using a new science and strategy based on innovation is of extreme need for cycles of businesses no linear, with models of re-use and recycling being used for economy of energy and energetic resources.

The use of renewable energy via systems based on energy extracted mainly from the water, the air, sun and from the biomass are the forms of energy systems that should be studied. Theoretical researches and cases of application should be studied. A detailed analysis about its use viability should be made. Aspects on its implementation and use, economical viability, market opportunities, forms of to storage the generated energy, and finally, their environmental restrictions should be taken into account.

4.5) Government leadership to treat energy problems regarding to its region of action is very important for the success of any program. Questions of the type: How can these strategies for energy efficiency be put into practice? Which is the cost for its implementation? Which the types of incentives and rules can be following for an acceptance in large scale? They require debates and multidisciplinary experiences that should be motivated and implemented mainly with urgency in the society by the government. A good suggestion would be the government to congregate a multidisciplinary team, formed by scientists of universities, institutes, private and public companies linked to areas mainly connected to: energy and renewable sources, social inclusion, ecology and environment, economy and energy efficiency, technological innovation, health and education.

\section{Conclusion}

In this article we presented the research strategies and development that the government would make it in account to implement its energetic matrix. This strategy seeks to solve not only the problem of the lack of energy, but also to generate solutions mainly for to solve the problems regarding to the use of fossil fuels. We suggested that the national grid be mainly formed of renewable sources of energy because this would decrease considerably the level of greenhouse effect gases in the atmosphere.

We also recommended that the generation be distributed to solve problems of the type: local waste of energy, unbalanced distribution of income, absence of garbage recycling, lack of social inclusion, safety in the supply and generation of energy, economical, environmental.

We showed that it is irrational to continue with the use of fossil fuels, because this is causing the overheating of the Earth with disastrous consequences in terms of floods, biomass losses, pollution, melting of the icecaps, floods causing social, ecological and economical disasters and diseases provoked by all of this together.

We pointed out that the problem is so serious and urgent that the Government should lead movements for its combat. The need of public politics that makes feasible the use of renewable energies will go not only soften the greenhouse effect as well as it can serve as an instrument of distribution of incomes, garbage recycling, use of small generating sources, technological development based on energy generated mainly from solar, wind and biomass sources. The government should also mobilize the society through movements that educate the population of the need of using the energy in a rational way, trying to use it without waste and with energy efficiency.

Nowadays, $80 \%$ of the world energy consumption are supplied by fossil fuels (WORLDWATCH, 2010). It is possible to operate necessary alterations in the world energetic matrix to minimize the global heating in the short, medium or long period.

Several are the existent technologies now to reach these objectives. Some countries, like Germany, Norway, Denmark, United Kingdom and United States already began to implement these solutions (Goldemberg, 2010). Brazil is still beginning this project, however due to its energy potential, it has everything to change its national energetic matrix composition, changing the use of fossil fuels gradually for the use of renewable sources of energy and of emission zero.

\section{References}

[1] Bonson, K. Como funcionará a terraformação de Marte. Editado por HowStuffWorks (EUA). Disponível em: $\quad<$ http://ciencia.hsw.uol.com.br/terraformacao-demarte.htm>. Acesso em: nov. 2010.

[2] Freudenrich, C. Como funciona Marte. Editado por HowStuffWorks (EUA). Disponível em:

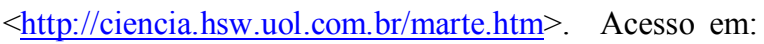
nov. 2010. 
[3] GODDARD Institute for Space Studies (GISS). Disponível em: <http://www.giss.nasa.gov/>. Acesso em: nov. 2010.

[4] Goldenberg, J. Mudanças Climáticas. Disponível em: $<$ http://www.mudancasclimaticas.andi.org.br/node/1126 > . Acesso em: nov. 2010.

[5] Metz, B., Davidson, O.R., Bosch, P.R., Dave, R., Meyer L.A. Mitigation of Climate Change, 2007. Contribution of Working Group III to the Fourth Assessment Report of the Intergovernmental Panel on Climate Change. Cambridge, and New York, 2007. Disponível em: $<$ http://www.ipcc.ch/publications and data/publications and data reports.htm>. Acesso em: nov. 2010.

[6] NASA - Earth Observatory Report. Why Does the Greenland Ice Sheet Matter? Disponível em: $<$ http://earthobservatory.nasa.gov/Features/>. Acesso em: nov. 2010.

[7] NATIONAL Weather Service Forecast Office. Disponível em: $<\underline{\text { http://www.nws.noaa.gov/climate/index.php?wfo=psr }>}$. Acesso em: nov. 2010(a).

[8] NATIONAL Weather Service Forecast Office. Record Warmth in 2010. Disponível em: $<$ http://www.srh.noaa.gov/lzk/?n=heat0710.htm $>$. Acesso em: nov. 2010(b).

[9] Nobre, C. A. e Assad, E. D. O Aquecimento Global e o Impacto na Amazônia e na Agricultura Brasileira. Disponível em: $\quad \underline{\text { http://mtc- }}$ m18.sid.inpe.br/col/sid.inpe.br/ePrint $\% 4080 / 2005 / 09.12$. 12.51/doc/v1.pdf $>$. Acesso em: nov. 2010.

[10] NOOA. National Oceanic and Atmospheric Administration. Carbon Dioxide, Methane Rise Sharply in 2007. Disponível em: $<$ http://www.noaanews.noaa.gov/stories2008/20080423 methane.html>. Acesso em: nov. 2010.

[11] Parry, M. L.; Canziani, O.F.; Palutikof, J. P.; Linden, P. J.; Van Der, J. P.; Hanson, C.E. Impacts, Adaptation and Vulnerability. Contribution of Working Group II to the Fourth Assessment Report of the Intergovernmental Panel on Climate Change, 2007. Cambridge, and New York. Disponível em: $<$ http://www.ipcc.ch/publications and data/publications and data reports.htm>. Acesso em: nov. 2010.

[12] PURDUE University. The top twenty US counties. Vulcan Project Website. 2008. Disponível em: $<\underline{\text { http://www.eas.purdue.edu/carbon/vulcan/images/count }}$ y.total.Cemit.SCnote.jpg >. Acesso em: nov. 2010.

[13] STORIES of American Energy Use. Disponível em: $<$ http://earthobservatory.nasa.gov/Features/AmericanCar bon/page2.php >. Acesso em: nov. 2010.

[14] UNITED States Global Change Research Program. Climate Change Impacts. Disponível em: $<$ http://globalchange.gov/>. Acesso em: nov. 2010.

[15] WEIER, J. A Delicate Balance: Signs of Change in the Tropics. Nasa: Earth Observatory. Disponível em: $<\underline{\text { http://earthobservatory.nasa.gov/Features/DelicateBalan }}$ ce/>. Acesso em: nov. 2010

[16] WORLDWATCH Institute. Climate Change Reference Guide. Disponível em: $<$ http://www.worldwatch.org/files/pdf/CCRG.pdf $>$. Acesso em: nov. 2010. 